\title{
ISOLATED INTRAMEDULLARY TUBERCULOMA OF THE SPINAL CORD: A RARE CASE REPORT
}

Sachin Khanduri ${ }^{1}$, Swati Goyal ${ }^{2}$, Saakshi Chhabra 3 , Samarjit Bhadury ${ }^{4}$, Aditi Jain Dey ${ }^{5}$

\section{HOW TO CITE THIS ARTICLE:}

Sachin Khanduri, Swati Goyal, Saakshi Chhabra, Samarjit Bhadury, Aditi Jain Dey. "Isolated Intramedullary Tuberculoma of the Spinal Cord: A rare case report". Journal of Evolution of Medical and Dental Sciences 2014; Vol. 3, Issue 51, October 09; Page: 12039-12042, DOI: 10.14260/jemds/2014/3589

\begin{abstract}
Intramedullary tuberculoma of the spinal cord is a rare form of tuberculous involvement. We report a case of isolated intramedullary tuberculoma in a young immune competent female with no evidence of tuberculous involvement in any other part of the body. Magnetic Resonance Imaging (MRI) cervical spine revealed an intramedullary nodular lesion at the level of C6C7 vertebrae associated with mild swelling of the cord due to the lesion and thick rim enhancement after intravenous (I.V) contrast administration. The administration of anti-tubercular treatment (ATT) resolved the symptoms of the patient and prevented the patient from unnecessary surgical exposure. Intramedullary tuberculoma can be completely resolved in most cases by early diagnostic evaluation and proper ATT administration and hence curbing the need of surgical intervention in most of the patients.
\end{abstract}

KEYWORDS: Intramedullary tuberculoma, contrast MRI, rim enhancement, antituberculous treatment.

INTRODUCTION: Tuberculosis is one of the major causes of morbidity in a developing country like India. To add to the disease burden the severity is on an up soar due to various immune compromised states, increasing multi drug resistant (MDR) and extensive drug resistant (XDR) tuberculosis. However, despite this wide prevalence, the incidence of central nervous system (CNS) involvement is extremely rare. (1) Majority of cases involving the CNS are intracranial. Tuberculoma affecting the spinal cord is extremely rare with incidence of 2: 1,00,000 in all patients affected with tuberculosis.(2) The ratio of intracerebral to intramedullary tuberculosis is $42: 1$ with $72 \%$ of all lesions involving the thoracic cord.(3)

CASE REPORT: A 25 year old female patient presented in out-patient department with 1 month history of weakness involving the right side of her body which was slightly progressive with no sensory loss. Her blood profile which included hemoglobin (Hb), total leukocyte count (TLC), differential leucocyte count (DLC), erythrocyte sedimentation rate (ESR) were all within normal limits. Her cerebrospinal fluid (CSF) examination revealed increased lymphocytes with increased proteins \& decreased sugar levels. Her chest skiagram, HRCT (high resolution computed tomography) thorax and MRI (magnetic resonance imaging) brain did not show any significant lesion.

Her systemic \& physical examinations were normal. On neurological examination all the cranial nerves were intact. On motor examination, there was wasting of thenar and hypothenar muscles of the right side with normal left sided examination. The tone and power in her right upper and lower limb was decreased. The power of right upper limb was $4 / 5$ and of right lower limb was $4 / 5$ with 5/5 power in both left upper and lower limbs. 
Sensory examination was normal. MRI cervical spine revealed an intramedullary nodular lesion at the level of C6-C7 vertebrae associated with mild swelling of the cord due to the lesion. The signals displayed were is intense to the cord on T1 weighted imaging (T1WI) with slightly swollen cord, is intense on T2 weighted imaging (T2WI) showing a hyper intense focus in the Centre (necrosis) with slight perilesional edema.

On short Tau inversion recovery (STIR) sequence, the Centre appeared is intense with hyper intense rim and perilesional edema. There was evidence of thick rim enhancement after the intravenous administration of gadolinium meglumine contrast. Considering the signal intensity, site, edema around the lesion, thick rim enhancement after IV contrast administration and the CSF analysis, the diagnosis of intramedullary tuberculoma was established.

The patient was administered anti-tubercular treatment (ATT) and marked improvement in her symptoms was noted within 2 months of beginning of ATT without the need for any surgical intervention. Our patient recovered fully and had no complains of weakness or relapse of the symptoms following the treatment.

DISCUSSION: Tuberculosis is an infectious disease caused mainly by Mycobacterium tuberculosis. It mainly affects the lungs but other parts of the body can also be involved in the disease process (extra pulmonary involvement). Tuberculosis of the CNS is an important and serious type of extra pulmonary involvement. The bacteria reach the CNS mainly by hematogenous route secondary to infection in other parts of the body. However, in almost one third of patients with CNS involvement by tuberculosis, there may be no evidence of extra neural tuberculosis. It mainly involves the neural and perineural tissues directly.

Spinal involvement is rare. Tuberculomas when present can be either intra dural extra medullary (IDEM), intramedullary or extradural. IDEM is the most common form of intraspinal tuberculous involvement.(4,5) It occurs mainly in young patients (late 20s to early 30s) and also involves women more than men. The thoracic cord is most commonly involved. The symptoms are mainly due to compression of spinal cord which mainly involves limb weakness which is generally progressive associated with paraesthesia and bowel and bladder dysfunction.

The MRI findings which prompt towards the diagnosis of a tuberculoma are (a) in early phase- isointense on both T1WI \& T2WI with uniform enhancement after the administration of contrast agent b) with development of caseation- central hyper intensity is noted on T2WI due to necrosis with liquefaction- target sign appearance. There is also expansion of cord due to oedema. If the MRI findings prompt the diagnosis of tuberculoma, a chest skiagram and a CT scan of the thorax should be done to look for pulmonary involvement, if any. Contrast studies should also be done, if indicated.

The differential diagnosis includes- spinal intramedullary tumors such as astrocytic glioma, ependymocytoma and hemangioblastoma. Antitubercular treatment (ATT) should be administered to the patient initially to look for any symptomatic relief and if there is deterioration of the neurological status of the patient or paradox increase in size of lesion following ATT, surgery should be considered as the ultimate resort.

CONCLUSION: Tuberculoma as a diagnosis should be borne in mind in all patients showing a lesion in the cord on MRI and contrast studies should be done. ATT should be preferred as the initial modality 
of treatment. With this conservative approach, surgeries can be avoided in many patients showing improvement with ATT itself.

\section{REFERENCES:}

1. Mac Donell AH. Baird R W, Bronze MS, Intra Baird RW, Bronze MS. Intramedullary tuberculomas of the spinal cord: Case report and review. Rev Infect Dis 1990; 12: 432-439.

2. Parmar H, Shah J, Patkar D, Varma R. Intramedullary tuberculomas. MR findings in seven patients. Acta Radiol 2000; 41: 572-7.

3. Nussbaum ES, Rockswold GL, Bergman TA, Erickson DL, Seljeskog EL. Spinal tuberculosis: a diagnostic and management challenge. J Neurosurg. 1995; 83 (2): 243-247.

4. Mathuria SN, Khosla VK, Banerjee AK. Intradural extra medullary tuberculous spinal granulomas Clin Neuro Neurosurg 1988; 90: 155-8.

5. Compton JS, Dorsch NW. Intradural extra medullary tuberculomas of the cervical spine: case report. J Neurosurg 1984; 60: 200-3.

FIGURE 1: MRI cervical spine sagittal section (a) T1WI shows isointense lesion in the cord (arrow) with slightly swollen cord (curved arrow) (b) T2WI shows isointense lesion in the cord with slight edema on both sides (curved arrow).

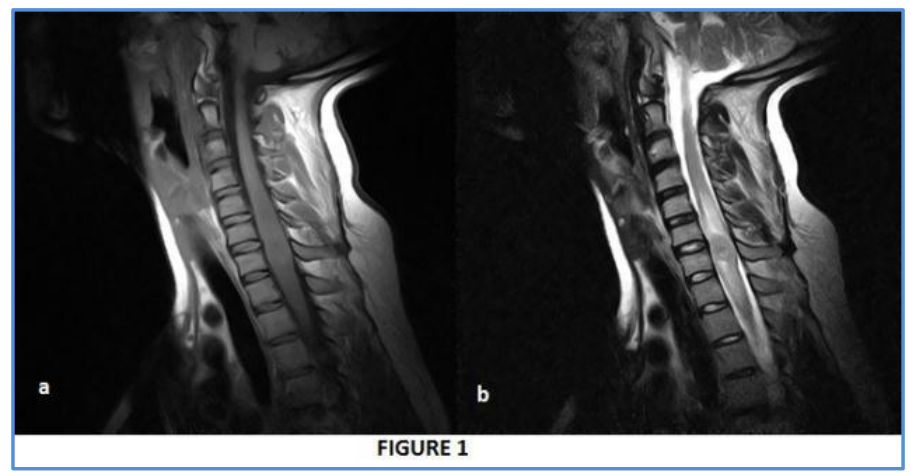

FIGURE 2: MRI cervical spine coronal section a) STIR showing isoechoic Centre with hyperintense rim with edema around the lesion b) Contrast study shows marked rim enhancement of the lesion (arrow).

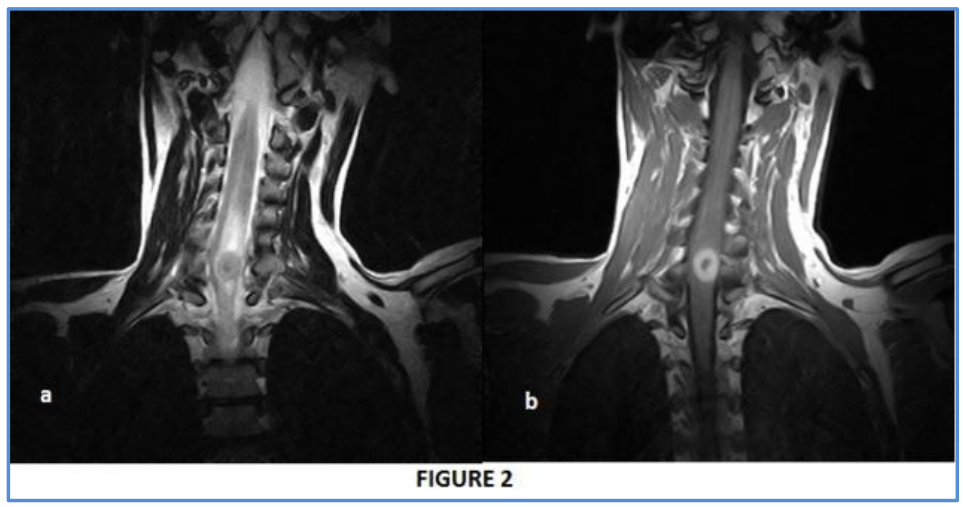




\section{CASE REPORT}

\section{AUTHORS:}

1. Sachin Khanduri

2. Swati Goyal

3. Saakshi Chhabra

4. Samarjit Bhadury

5. Aditi Jain Dey

\section{PARTICULARS OF CONTRIBUTORS:}

1. Professor, Department of Radio-diagnosis, Era's Lucknow Medical College and Hospital, Lucknow.

2. Junior Resident, Department of Radiodiagnosis, Era's Lucknow Medical College and Hospital, Lucknow.

3. Junior Resident, Department of Radiodiagnosis, Era's Lucknow Medical College and Hospital, Lucknow.
4. Professor, Department of Radio-diagnosis, Era's Lucknow Medical College and Hospital, Lucknow.

5. Junior Resident, Department of Radiodiagnosis, Era's Lucknow Medical College and Hospital, Lucknow.

\section{NAME ADDRESS EMAIL ID OF THE CORRESPONDING AUTHOR:}

Dr. Sachin Khanduri, \# C-149, Indira Nagar,

Lucknow.

Email: sasho0622@hotmail.com

Date of Submission: 17/09/2014.

Date of Peer Review: 18/09/2014.

Date of Acceptance: 01/10/2014.

Date of Publishing: 09/10/2014. 